\title{
Emergency care and resuscitation plans
}

\author{
(@) $(1)$ OPEN ACCESS
}

\begin{abstract}
David Pitcher immediate past president of Resuscitation Council (UK), retired consultant cardiologist ${ }^{1}$, Zoe Fritz Wellcome fellow in society and ethics at Warwick University, consultant acute physician, Cambridge University Hospitals ${ }^{2}$, Madeleine Wang independent patient advocate ${ }^{3}$, Juliet A Spiller consultant in palliative medicine ${ }^{4}$
\end{abstract}

${ }^{1}$ Resuscitation Council (UK), Tavistock House, London WC1H 9HR, UK; ${ }^{2}$ Department of Acute Medicine, Cambridge University Hospitals, Addenbrooke's Hospital, Cambridge CB2 OQQ, UK; ${ }^{3}$ Tugby, Leicestershire, UK; ${ }^{4}$ Marie Curie Hospice Edinburgh, UK

When a person's heart or breathing stops and the cause is reversible, immediate cardiopulmonary resuscitation (CPR) offers a chance of life. However, when a person is dying-for example, from organ failure, frailty, or advanced cancer-and his or her heart stops as a final part of a dying process, CPR will not prevent death and may do harm.

"Do not attempt CPR" (DNACPR) decisions were first documented in the 1970s, to try to protect people from receiving CPR that they did not want, that would not work, or would not give them overall benefit. This approach of making CPR decisions separately from decisions about other treatments has been challenging for clinicians and patients and has caused problems. ${ }^{1-4}$ Despite national guidance in the UK (see "Further educational resources" box), misunderstandings, poor communication, and inconsistent DNACPR documentation persist. ${ }^{4}$ Exploring and achieving a shared understanding among patient, family, and healthcare team of realistic and individualised care preferences may sometimes be done badly or not even attempted.

Here we draw on evidence (box 1), collated for a broader project, to outline how clinicians might plan with their patients. We offer suggestions on how clinicians and their patients might better think ahead, consider, discuss and record patient-centred recommendations, not only about CPR but also other elements of emergency care and treatment. In a linked article Fritz et al explain why a change in practice and culture, timing and context of these conversations is needed. ${ }^{7}$

\section{Who may benefit from having a plan for a possible future emergency?}

Consider offering this to people with complex health needs, life limiting conditions, or illnesses that predispose to sudden deterioration or cardiorespiratory arrest (box 2). Ask yourself whether a person is likely to have a deterioration for which recommendations agreed in advance could help immediate decision making.

Think about the situations in which others may have to make immediate decisions about care and treatment for that person in their individual circumstances. These will vary substantially between individuals and might include a sudden acute illness (such as heart attack, stroke, sepsis), deterioration in a long term condition (such as advanced kidney failure, heart failure, lung disease, frailty), or sudden cardiac or respiratory arrest.

Other people may ask to make a plan because they want to record their preferences in case of an unforeseen future emergency.

If people have the capacity for relevant decisions, consult them about current and anticipatory treatment decisions-in the UK this is a legal requirement. If they lack capacity, consult those close to them, where practicable and appropriate (see box 3 ). If family or other carers cannot be consulted immediately, make and document any necessary urgent decisions, ideally agreed with other team members, along with a clear plan to consult as soon as possible. 


\title{
What you need to know
}

- An emergency care plan allows clinicians to discuss and record patient preferences in advance, not only regarding cardiopulmonary resuscitation, but all aspects of care and treatment in an emergency

- An emergency care plan provides recommendations for care and treatment for future scenarios when people might not have the capacity to communicate their preferences

- Tailor the emergency care plan to consider the most likely individual situations, such as a sudden acute illness, deterioration in a long-term condition, or sudden cardiac or respiratory arrest

\section{Box 1: Sources of evidence}

This article draws on an evidence synthesis, ${ }^{4}$ two systematic reviews, ${ }^{56}$ and consensus discussions in a group of stakeholders covering a broad range of care settings and specialties. These stakeholders included nurses, patient representatives, ambulance clinicians, and doctors, who together have developed the ReSPECT process in the UK. ${ }^{7}$ The principles described are applicable more generally to discussions about advance planning for future emergencies.

\author{
Box 2: Some triggers for discussing emergency care plans \\ - Requests by the people themselves \\ - Recognition of long term or complex medical needs-discussions can be started in hospital clinics and wards as well as in general \\ practice \\ - Diagnosis of a life limiting condition—recognition that end-of-life care will be needed \\ - Admission to hospital, especially with an acute illness of any kind \\ - Admission to a care home or nursing home \\ - Identified risk of acute deterioration, cardiac arrest, or death
}

\section{Box 3: What to do when people lack capacity for making decisions about emergency care plans}

- Discussion with family or other representatives should follow a similar sequence to discussion with a patient (see within "How to have a better conversation")

- Try to establish the choices that the person would have made if they had capacity; find out if they have an advance care plan or advance statement recording their preferences, or a legally binding instruction such as an Advance Decision to Refuse Treatment (England \& Wales)

- Help the family to understand their role: to advise the healthcare team what the patient would have been likely to decide, had he or she had capacity, and what they believe to be in the patient's best interests, but not to make clinical decisions

- The senior responsible clinician has ultimate responsibility to make decisions in the person's best interests or for their overall benefit

- It is common for relatives to feel that they are being asked to make decisions: take care to avoid this. Explain clearly and exactly how you are asking relatives to help you make the right decision for the patient, and remember to reinforce the same message afterwards, because at these stressful times families often forget or misinterpret what has been said to them

In the UK, the exception to this is if someone has been appointed as legal proxy with powers to make decisions about life sustaining treatment: that person's decisions must be viewed as binding, as long as they clearly serve the patient's best interests.

\section{What is the difference between an emergency care plan and an advance or anticipatory care plan?}

Emergency care plans provide concise, relevant, rapidly accessible clinical recommendations for use in an emergency. Advance or anticipatory care plans are more detailed, often completed by the patient, and may focus specifically on end-of-life care. The two plans are complementary; they may be developed together, or completion of one may prompt consideration of the other. If your patient has or is making an advance care plan, suggest also developing an emergency plan. If you are developing an emergency plan during an acute illness, consider whether a more detailed advance or anticipatory care plan is needed or wanted at that time, or may be needed or wanted later.

\section{How to have a better conversation Consider timing}

Qualitative studies suggest that conversations are best initiated when people are relatively well with time to discuss treatment options and consider their preferences before a crisis occurs. ${ }^{89}$ Ideally, discussion will involve a health professional who knows the person well. For many, the community healthcare team will be best-placed to initiate a conversation about an emergency care plan. In some instances, further conversations or liaison with other professionals such as hospital specialists or palliative care teams may be needed. Give people ample opportunity for discussion.

\section{Frame a conversation}

Explain to the patient that the aim is to produce recommendations which can guide immediate decision making in a future emergency in which the person does not have the ability or capacity to make or express choices. A succinct emergency care plan can provide rapidly accessible information about a person's condition, preferences, and agreed recommendations for care. This helps professionals faced with an emergency to make immediate decisions and deliver appropriate, desired care to a person who has lost capacity to make or express choices. Avoid jargon. Don't assume that 
patients or families understand why making a plan is needed. Families have told us that they did not understand why clinicians were so keen to record a decision about CPR for patients who were dying or critically ill.

Give balanced information and advice. Avoid terms such as "futility" and "ceiling of treatment," which can undermine people's confidence and compromise discussion if they interpret these as meaning that nothing more can or will be done. Discuss treatment to be given, not just treatment to be withheld; this improves the nature of conversations. ${ }^{10}$

A mixed methods study found that including a recommendation whether to attempt CPR within overall goals of care (rather than on a separate DNACPR form) is associated with improved patient care and a reduction in misunderstandings associated with DNACPR. ${ }^{10}$

Therefore, it may be helpful not to focus only on CPR, or cardiac arrest, or completing a form. Instead, talk with patients about:

- What might be ahead for them

- What matters most to them,

- What their values are

- Which realistic treatment and care options may help or not help them.

When you come to discussing CPR:

- Avoid overemphasising brutality: one relative said that several doctors told her CPR would involve "jumping up and down on the ribs, maybe causing fractures ... giving electric shocks ... putting needles in." She said it was "as if this is what they had all been taught to say."

- Quoting average survival rates can be misleading. The chance of survival from cardiorespiratory arrest ranges from zero to almost $100 \%$, according to each person's individual condition and the circumstances of the event. Discussion should focus on the person's own chance of survival, given his or her clinical condition. Clinicians advising a person admitted to hospital may consider using a score to predict the chance of neurologically intact survival ${ }^{11}$ if this outcome matches that person's values. Remember that people often have unrealistic expectations, in part due to television portrayals of CPR. ${ }^{12}$

The points below may help clinicians to progress a conversation. Start by discussing the person's understanding of his or her condition and circumstances, and correcting any misunderstandings or unrealistic expectations.

Explain that people have different views about types of treatment that they would want if they were suddenly ill and could not make choices. Establishing people's views and making recommendations in advance can help to ensure that they get the best treatment. ${ }^{13}$

Explore what aims of treatment are important to them in their situation:

- Some people want to consider all treatments to try to sustain life

- For others comfort is the priority

- Many will want a balance between these-the type of scale shown in the infographic can sometimes facilitate this part of the conversation.

Explore what is important to them for the future. For example, this may be independent mobility, communicating with friends and family, the ability to read or ability to listen to music, being cared for at home.
Discuss any realistic treatments that could help achieve their aims and decide together what recommendations to record. These might refer both to treatments that they would like to be considered for and those that they would not want.

Discuss CPR in the context of prognosis, goals of care, and other treatment choices. ${ }^{14}$

- If there is a realistic possibility that CPR would restart their heart and breathing, explain its chances of restoring a length and quality of life that they would want, and record the resulting agreed recommendation.

- If there is no realistic likelihood that CPR will work, because the person dying from an advanced and irreversible condition, ${ }^{15}$ explain this sensitively unless to do so would cause harm.

- If a person with a life limiting condition wants to die at home, document this and, after explaining the need for it, record a recommendation not to attempt CPR. If relevant, discuss and record circumstances (if any) in which the person would want to be taken to hospital.

\section{Recording preferences and recommendations}

Having identified goals of care and the patient's preferences, decide together what clinical recommendations to record. Ensure that you record recommendations in clear, unambiguous language that will be understood easily by those needing to read them in an emergency — such as an ambulance clinician, nurse, or out-of-hours doctor who may not have met the person before. In the UK an emergency care plan is not an "order" and is not legally binding; this may not be the case in some other countries. Nevertheless, a clinician responding to an emergency will need to be able to justify overruling previously agreed and documented recommendations. Box 4 gives suggestions on when to review recommendations

ReSPECT is a new emergency care plan developed in the UK to support conversations and record recommendations arising from discussion between clinician and patient or those close to the patient. Box 5 lists three hypothetical scenarios for recording of emergency care plans, and the data supplements show the completed ReSPECT forms. Such a summary plan should remain with the patient. Further information about the ReSPECT process can be accessed at www.respectprocess.org.uk.

\section{Children and young people}

The same principles can be used for people of all ages (see box $6)$.

\section{Specific challenges}

Communication-People welcome these conversations, but they can be delicate, requiring acknowledgment of mortality. Members of the public have emphasised that specific training is important to support clinicians in developing the necessary skills; they would welcome mandatory sessions, perhaps alongside CPR training. Interviews with elderly patients suggest that it can be helpful to discuss desired outcomes rather than focusing on specific treatments. ${ }^{16}$

Avoiding discrimination-Advanced age or a disability on their own are not appropriate reasons for recommending withholding potentially life sustaining treatment. ${ }^{17}$ Discrimination may occur also if a person is subjected to CPR with no realistic chance of benefit, simply because they are younger or because of an assumption that they would want this. 


\section{Box 4: When should documentation be reviewed?}

- If the person or close family or friends request this

- If the person's condition changes

- If the person moves from one care setting to another (including in-hospital transfer, such as to or from intensive care)

Frequency of review should be planned according to each person's individual situation (frequent review for an acute illness but not usually for an advanced, irreversible, and terminal illness). A fixed review or expiry interval risks encouraging insufficiently frequent review for some people, and inadvertent expiry (leading to disregard of the recommendations) for some whose recommendations needed no review.

\section{Box 5: Patient stories}

Patient story 1

A 92-year-old lady is physically and mentally well and independent. She develops pneumonia and is admitted to hospital. ReSPECT is discussed with her. She is clear that, while she would like to continue living, she would only want to do so if she can remain independent. She does not want to "end up in a home" or be unable to do things for herself. She says explicitly "I don't want a lingering death; when my time has come, it's come."

The doctor emphasises that that they hope that treatment with antibiotics will clear her infection, but that "An infection like this is always a bit of a risk for someone of your age." It's possible that she could get worse before the antibiotics start to take effect. He discusses the possible option, if she gets worse and is struggling badly with her breathing, to move her to the intensive care unit (ICU) for treatments such as high-flow oxygen or possibly to consider "using a machine to help her lungs for a bit."

After further explanation of what would be involved, she decides that she would be willing to go to ICU for treatment but would not want "invasive" ventilation. She and the doctor agree that if she became worse and it became apparent that she was not going to recover, or that she would end up in a very dependent state, they could stop trying to cure her infection and concentrate on treatments to make sure that she was comfortable. The doctor explains also that, if she got worse and died, her heart and breathing would stop as part of the natural process of dying, and trying to start them again wouldn't prevent her death. She is quick to say that she "certainly wouldn't want to be resuscitated" if this happened. The ReSPECT form is completed (see supplementary ReSPECT form 1 at www.bmj.com/content/bmj/356/ bmj.j876/related\#datasupp).

In the event, she improves with antibiotic treatment and chest physiotherapy and is discharged home after 5 days. On discharge, the conversations about ReSPECT are revisited, and her preferences are unchanged. The agreed clinical recommendations are therefore communicated to her GP and she is offered the ReSPECT form to keep with her, so that it will be available immediately if she has a further sudden health problem.

\section{Patient story 2}

A 51 -year-old woman has advanced, metastatic pancreatic cancer. She understands that she is not expected to live for more than about 6 months. Palliative chemotherapy was complicated by a severe urinary tract infection, treated in hospital, and she decided that she did not want any more chemotherapy. After this, she told her GP also that she didn't want to go back into hospital "unless it was absolutely necessary."

The GP asks what she means: would she want to go back if she had another severe infection and might die from it?

"No", she says. She would want to have treatment at home and, whilst she was willing to be given antibiotics at home for another infection she would want the main focus of her treatment to be on ensuring her comfort, not trying to prolong her life for perhaps a few weeks or a few days. ReSPECT is discussed with her, and a form completed (see ReSPECT form 2 at www.bmj.com/content/bmj/356/bmj.j876/related\# datasupp). Some drugs, including an opiate, are left in the house as a "just in case" pack.

Two weeks later she develops breathlessness and pain, and becomes confused. Her family call 999; an ambulance first-responder arrives, asks if she has a ReSPECT form and is shown it. As there was a clear plan for her to be treated at home, he does not call for an ambulance, and helps the family to contact her palliative care nurse, so that she can receive her "just in case" treatment without delay, together with ongoing care and support for her and her family.

\section{Patient story 3}

A 48-year-old man with cerebral palsy and epilepsy has recurrent admissions for aspiration pneumonia, sometimes requiring admission to the intensive care unit (ICU); sometimes these admissions have been brief; sometimes it has been difficult to wean him off the ventilator. His GP has a ReSPECT conversation with him about what is important to him; it is clear that he enjoys life and, although he has found the long recovery periods following ICU admissions arduous, he would do it again. A ReSPECT form is completed, recording an agreed recommendation for full, active treatment in the event of further pneumonia A ReSPECT form is completed, recording an agreed recommendation for full, active treatment in the event of further pneumonia (see ReSPECT form 3 at www.bmj.com/content/bmj/356/bmj. j876/related\#datasupp); details are communicated to the local hospital.

When he has a prolonged seizure a few months later, the paramedics follow the recommendations on his ReSPECT form and take him to the emergency department, telephoning his emergency contacts from the ambulance. The emergency physicians read the ReSPECT form, make sure that he has full supportive care during his post-ictal phase, and assess and treat him for recurrent aspiration. This requires admission to the ICU for a brief period of ventilation, after which he recovers, is discharged and continues to enjoy life.

\section{Box 6: Emergency care plans for infants, children, and young people}

- Some clinicians may be unfamiliar with complex, potentially life limiting conditions that can affect infants, children, or young people. In such situations an emergency care plan can provide:

- A clear, succinct record of the person's preferences and agreed recommendations for his or her care in an emergency

- A familiar format that is complementary to more comprehensive documents such as the Child \& Young Person's Advance Care Plan (cypacp.nhs.uk)

- A plan with the format used for adults may help to provide continuity when a young person transfers from paediatric to adult care

- Preferences will commonly be captured from several people, usually focused through discussions with those holding parental responsibility

- Whenever possible, children and young people should be consulted and their views included in recorded preferences

- Children and young people who are competent to make choices about their emergency care should be given the chance to lead these discussions

\section{Adopting a patient's perspective-When discussing} life-sustaining treatments and their chance of success, define success from the person's perspective, not in terms of what you (or those close to the patient) might consider an acceptable duration of survival or quality of life. Help people to express realistic preferences for their future care and treatment in a 
future emergency and to understand that these cannot be used to demand specific treatments.

Uncertainty-Many clinical situations involve some uncertainty. Where this exists, be open and honest. Patients and those close to them need support to cope with uncertainty. If you do not feel competent to do this, seek help from a colleague who does. Explore training opportunities to improve your skills and confidence for future occasions.

Resolving disagreement_-Provide further explanation (involving experienced colleagues if necessary) to try to achieve shared understanding of the basis for proposed recommendation(s) and agree a shared decision. If disagreement persists, offer and arrange a second opinion before recording any

recommendations. Record only agreed recommendations on an emergency care plan. Document details of all discussions in the person's health record, including details of any disagreement. Where there is persistent disagreement over critical elements of care or treatment, legal advice may be needed.

Contributors: Peter-Marc Fortune, associate clinical head of Royal Manchester Children's Hospital and president of the Paediatric Intensive Care Society, reviewed the manuscript and drafted the content of box 5. Peter Davies, general practitioner, Halifax, and Care Quality Commission regional advisor in general practice, North of England provided some initial suggestions for the manuscript content.

Competing interests: All authors and contributors have been involved in the RESPECT project. This is a collaborative project, facilitated by the Resuscitation Council (UK). As part of the project we have produced new documentation to support emergency care planning for patients in the UK. As members of the Resuscitation Council (UK), DP and ZF have conducted promotion of and education in high quality resuscitation and received travel and accommodation expenses for these activities. ZF has also received research grants to evaluate emergency care plans. JAS has worked for Marie Curie, NHS Scotland, and Scottish Government on DNACPR policy and advance care plans, and received travel and accommodation expenses for these activities.

Provenance and peer review: Commissioned; externally peer reviewed. Patient consent not required (patients hypothetical).

1 Fritz Z, Fuld J. Ethical issues surrounding do not attempt resuscitation orders: decisions, discussions and deleterious effects. J Med Ethics 2010;36:593-7. doi:10.1136/jme.2010. 035725pmid:20675736.
2 National Confidential Enquiry into Patient Outcome and Death (NCEPOD). Time to Intervene. NCEPOD. London 2012. www.ncepod.org.uk/reports.html.

3 Beed M, de Beer T, Brindley PG. Two decades of British newspaper coverage regarding do not attempt cardiopulmonary resuscitation decisions: Lessons for clinicians. Resuscitation 2015;86:31-7. doi:10.1016/j.resuscitation.2014.10.002pmid:25449344.

4 Perkins GD, Griffiths F, Slowther A-M, et al. Do-not-attempt-cardiopulmonary-resuscitation decisions: an evidence synthesis. Health Serv Deliv Res 2016;4.

5 Field RA, Fritz Z, Baker A, Grove A, Perkins GD. Systematic review of interventions to improve appropriate use and outcomes associated with do-not-attempt-cardiopulmonary-resuscitation decisions. Resuscitation 2014;85:1418-31. doi:10.1016/j.resuscitation.2014.08.024pmid:25195071.

6 Mockford C, Fritz Z, George R, et al. Do not attempt cardiopulmonary resuscitation (DNACPR) orders: a systematic review of the barriers and facilitators of decision-making and implementation. Resuscitation 2015;88:99-113. doi:10.1016/j.resuscitation.2014.11. 016pmid:25433293.

7 Fritz Z, Slowther AM, Perkins G. Resuscitation policy should focus on the patient, not the decision. BMJ 2017;356:j813. doi:10.1136/bmj.j813

8 Seymour J, Gott M, Bellamy G, Ahmedzai SH, Clark D. Planning for the end of life: the views of older people about advance care statements. Soc Sci Med 2004:59:57-68. doi: 10.1016/. socscimed.2003.10.005pmid:15087143.

9 Mullick A, Martin J, Sallnow L. An introduction to advance care planning in practice. $B M J$ 2013;347:f6064. doi:10.1136/bmj.f6064pmid:24144870.

10 Fritz Z, Malyon A, Frankau JM, et al. The Universal Form of Treatment Options (UFTO) as an alternative to Do Not Attempt Cardiopulmonary Resuscitation (DNACPR) orders: a mixed methods evaluation of the effects on clinical practice and patient care. PLoS One 2013;8:e70977. doi:10.1371/journal.pone.0070977pmid:24023718.

11 Ebell MH, Jang W, Shen Y, Geocadin RG. Get With the Guidelines-Resuscitation Investigators. Development and validation of the Good Outcome Following Attempted Resuscitation (GO-FAR) score to predict neurologically intact survival after in-hospital cardiopulmonary resuscitation. JAMA Intern Med 2013;173:1872-8. doi:10.1001/ jamainternmed.2013.10037pmid:24018585.

12 Harris D, Willoughby $\mathrm{H}$. Resuscitation on television: realistic or ridiculous? A quantitative observational analysis of the portrayal of cardiopulmonary resuscitation in television medical drama. Resuscitation 2009;80:1275-9. doi:10.1016/j.resuscitation.2009.07. 008pmid:19699021.

13 Detering KM, Hancock AD, Reade MC, Silvester W. The impact of advance care planning on end of life care in elderly patients: randomised controlled trial. BMJ 2010;340:c1345. doi:10.1136/bmj.c1345pmid:20332506.

14 Musa I, Seymour J, Narayanasamy MJ, Wada T, Conroy S. A survey of older peoples' attitudes towards advance care planning. Age Ageing 2015;44:371-6. doi:10.1093/ageing/ afv041 pmid:25917242.

15 Caldwell G. Full cardiopulmonary resuscitation should not be used for ordinary dying BMJ 2015;351:h3769. doi:10.1136/bmj.h3769pmid:26173441.

16 Rosenfeld KE, Wenger NS, Kagawa-Singer M. End-of-life decision making: a qualitative study of elderly individuals. J Gen Intern Med 2000;15:620-5. doi:10.1046/.1525-1497. 2000.06289.xpmid: 11029675

17 Heslop P, Blair P, Fleming P, et al. The Confidential Inquiry into premature deaths of people with learning disabilities (CIPOLD). Norah Fry Research Centre. Bristol 2013. www.bristol.ac.uk/cipold/reports/.

Published by the BMJ Publishing Group Limited. For permission to use (where not already granted under a licence) please go to http://group.bmj.com/group/rights-licensing/ permissions

This is an Open Access article distributed in accordance with the Creative Commons Attribution Non Commercial (CC BY-NC 4.0) license, which permits others to distribute, remix, adapt, build upon this work non-commercially, and license their derivative works on different terms, provided the original work is properly cited and the use is non-commercial. See: http://creativecommons.org/licenses/by-nc/4.0/ . 


\section{Education into practice}

- Are you familiar with your organisation's policy on decisions about CPR?

- What training for important conversations about CPR and other treatment decisions does your organisation provide to its staff?

\section{Further educational resources}

- British Medical Association, Resuscitation Council (UK), Royal College of Nursing. Decisions relating to cardiopulmonary resuscitation. 3rd ed, 1st rev. 2016. www.resus.org.uk/dnacpr/decisions-relating-to-cpr/

- General Medical Council. Good medical practice: Explanatory guidance. 2013. www.gmc-uk.org/guidance/ethical_guidance.asp

- Royal College of Nursing. Getting it right every time. Fundamentals of nursing care at the end of life. 2015. http://rcnendoflife.org.uk/

- NHS Scotland. Realistic medicine. Chief medical officer's annual report 2014-15. www.gov.scot/Resource/0049/00492520.pdf.

- General Medical Council, National Council for Palliative Care. Talking about end of life care: communication. https://vimeo.com/ 159875499 .

\section{How patients were involved in the creation of this article}

One of the authors, MW, is one of four patient/public representatives on the consensus group that developed the ReSPECT process and the recommendations expressed in this article. She was involved in planning the article, review of drafts, and approval of the manuscript. The development of ReSPECT included both a public consultation and discussion in patient focus groups.

Another member of the public with relevant personal experience, who preferred to remain anonymous, emphasised the importance of specific training for clinicians, reviewed the manuscript, and made further suggestions.

Another patient representative reminded us that all members of the consensus group are themselves potential patients and may have family members or friends likely to benefit from emergency care planning, 